\title{
SHORELINE CHANGE DETECTION AND COASTAL EROSION MONITORING USING DIGITAL PROCESSING OF A TIME SERIES OF HIGH SPATIAL RESOLUTION REMOTE SENSING DATA
}

\author{
Vassilakis Emm. ${ }^{1}$, Tsokos A. ${ }^{2}$ and Kotsi E. ${ }^{1}$ \\ ${ }^{1}$ National and Kapodistrian University of Athens, Faculty of Geology and Geoenvironment, 15784, \\ Athens, Greece,evasilak@geol.uoa.gr,ekotsi@gmail.com \\ ${ }^{2}$ National Technical University of Athens, Department of Civil Engineering, Laboratory of Harbor \\ Works(LHW), atsokos@gmail.com
}

\begin{abstract}
The long term change of the shoreline is a phenomenon, which is factored in the design of construction projects along the coastal zone. This study presents a methodology that aims to quantify the shoreline displacement rate. The described methodology involves the interpretation of different remote sensing data types, which make up a quite dense time series of representations for the coastline spanning from 1987 to 2012. The representation of the shoreline is based on geometrically corrected (ortho-rectified), historical, analogue, panchromatic, high resolution aerial photos of the area (1987, 1996) and latest generation, digital, multispectral, high resolution satellite images (2000, 2008, 2012). In all cases the images were digitally processed and optically optimized in order to produce a highly accurate representation of the shoreline in each time period. All the data were imported in a Geographic Information System platform, where they were subjected to comparison and geo-statistical analysis. A large number of sections perpendicular to the coast (every 100 meters) was drawn and the relative motion of the coastline was calculated for each of them. The average rate of the calculated erosion is in the order of $24 \mathrm{~mm} / y$ ear whilst extreme rates of $1 \mathrm{~m} / y e a r$ were also observed in specific positions.
\end{abstract} Keywords: Ikonos, Worldview, photogrammetry, DSAS.

\section{Пєрі́ $\eta \psi \eta$}

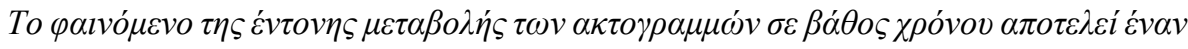

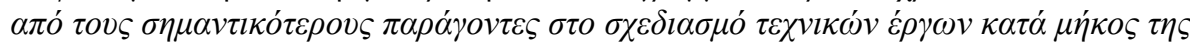

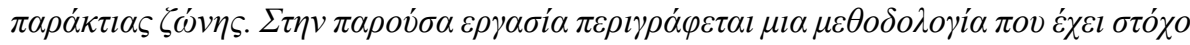

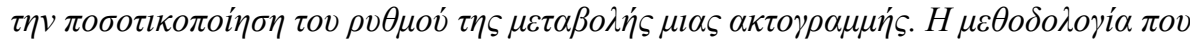

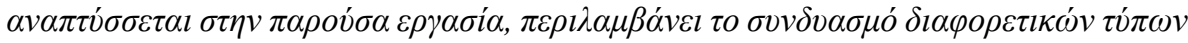

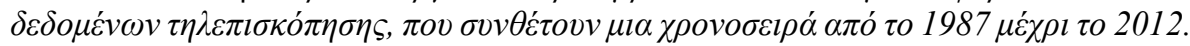

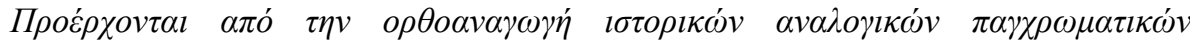

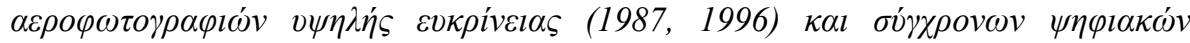

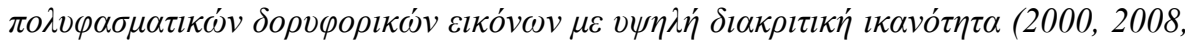

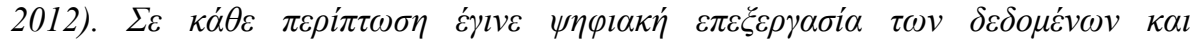

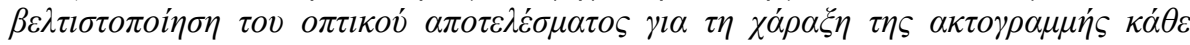

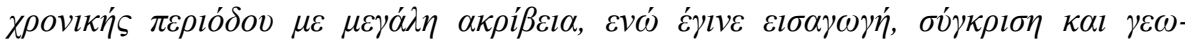




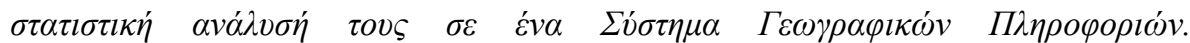

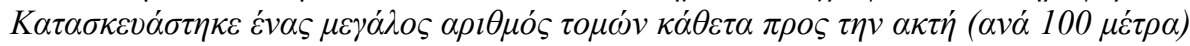

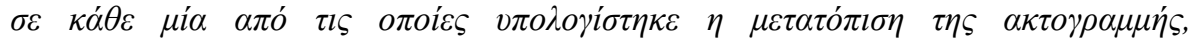

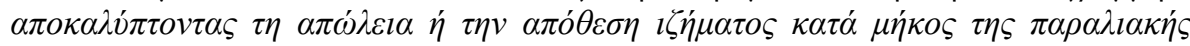

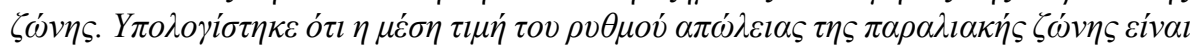

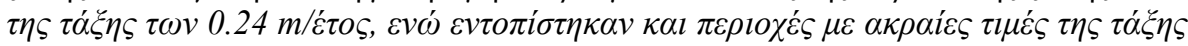

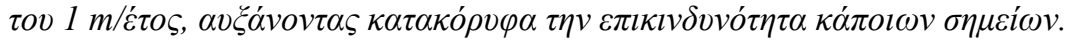

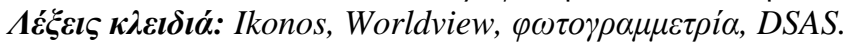

\title{
1. Introduction
}

The radical change of the shoreline during time is one of the most important factors to be taken into consideration when designing structures along the coastline (De Pippo et al., 2008; Anthoff et al., 2010; Nicholls and Hoozemans, 1996). Given that a large number of human activities take place near or along the coastline (Salman et al., 2004) it is important to point out the dangerous areas and quantify beach erosion with the highest possible accuracy (Evans et al., 2004). A change in the topography along the shoreline, as well as severe erosion phenomena have been observed in large areas due to human presence and activities (Kloehn et al., 2008; Rijn, 1998). The study of these changes during the last decades can give the scientists a chance to calculate the rate of shoreline change using various methods (Zuidam and Van Zuidam-Cancelado, 1979; Alhin and Niemeyer, 2009). In order to estimate this rate of evolution, a long time series of data going back in time is needed (Malthus and Mumby, 2003; Boak and Turner, 2005). These data usually involve remote distance observations, such as aerial photographs or digital satellite images. Digital processing of the aforementioned data can provide important information on the sampling period. The process of digital interpretation of such data is of utmost importance so as to create ortho-corrected data-sets for each period and results in the derivation of comparable data and implications for the environmental impact of the phenomena (Vassilakis, 2010). Moreover, the collection of field data and their validation is important in order to specify the real causes of the changes in the shoreline, which can be related to physical processes, human activity or both (Valaouris et al., 2014).

\section{Investigation area}

The area of interest is situated at the southern shoreline of the Gulf of Corinth where the beach zones are under neotectonic control. A large number of active fault zones with general inclination towards the north develop parallel to the current shoreline and contribute to the constant widening of the gulf. The widening happens along NNW-SSE direction and the rate of displacement is $14 \mathrm{~mm} / \mathrm{year}$ according to GPS measurements (McClusky et al., 2000; Hollenstein et al., 2008; Vassilakis et al., 2011). This phenomenon has a direct impact on the change of the shoreline position. The severe changes in the position of the shoreline in the long term are one of the most important issues due to hazard assessment at the selected area of the Gulf of Corinth.

A significant number of either small or larger river mouths are located along the entire area of the southern coastline of the Gulf of Corinth, feeding it up with large quantities of eroded material since Pleistocene. The deposited beds at the estuaries are usually found tilted towards upstream (Vassilakis et al., 2007). The result of these tectonic movements is the continuous uplifting of the northern beaches of Peloponnesus and consequently intensive erosion in depth along with canyon development. This, in turn, contributes in the constant input of sediment in the deltaic areas. In that sense, alluvium and contemporary material transported through rivers consisting of coarse material like sand and breccia can be found along the shoreline. Some berms of small thickness have also been observed in specific areas.

The morphological slopes along the beach zone are mild with values up to $5 \%$. The in situ measurements verify the mild slopes and the lack of scarps, at least in the area described in this paper. The area selected for the application of the specific methodology has an overall length of 14.5 
$\mathrm{km}$ and lies between the Town of Sikyon and the Town of Xilokastro, where large residential and tourist development has occurred during the last decades, whilst along the shoreline various works have been constructed to protect the beach from erosion.

\section{Methodology}

This study was conducted using two different types of data. Historical analog panchromatic aerial images of high resolution (Zuidam and Van Zuidam-Cancelado, 1979) and contemporary digital high resolution multi-spectral satellite images. The acquisition of the aerial photographs took place during 1987 and 1996, while the satellite images where acquired during 2000, 2008 and 2012 (Fig.1).

The geometrically corrected data were projected in the same reference system, covering a total time period of 25 years. At all stages of the described methodology the Greek Geodetic Reference System of 1987 (GGRS '87) was used (Mugnier, 2002). The panchromatic aerial photographs were scanned with a high resolution scanner (1200 dpi) (Chaaban et al., 2012) and were ortho-rectified using photogrammetric software (Vassilakis and Papadopoulou-Vrynioti, 2014). During the orthorectification procedure of both the scanned aerial photographs and the digital satellite images, a high resolution digital elevation model was used. The latter reached the spatial resolution of 10 meters and was created using contours and height measurements from topographic maps of scale 1:5,000. The photogrammetric software was used to identify tie points among the aerial and satellite images as well as control points (Moore, 2000). The selected control points are points of known coordinates $(\mathrm{X}, \mathrm{Y})$ and elevation $(\mathrm{Z})$.

The process of ortho-rectification led to the production of two panchromatic mosaics with 1 meter spatial resolution, one for each year of aerial data acquisition (1987 and 1996). In a similar manner, the satellite images were ortho-rectified to create three multi-spectral mosaics for the years 2000 , 2008 and 2012. The satellite images which were used in this work were Ikonos-2 (for the years 2000 and 2008) with a spatial resolution of 1 meter and Worldview-2 (for the year 2012) with a spatial resolution of 0.5 meter. The ortho-rectification procedure was based on the initial data and resulted 16-bit images.

The use of the visible part of the electro-magnetic spectrum for the collected data of remote sensing provides a uniformity and objectivity in the methodology. Using image processing techniques for interpreting all images, the shoreline was digitized for all the different time periods. The most difficult part was to identify with high accuracy the separation points between the waterbody and the land (Gens, 2010). In order to accurately project the shoreline, the histogram of each image was equalized and in some cases a weight coefficient was used. The latter was different for every aerial photograph, taking into account the details of the flight and the relative position of the sun.

An important feature of the present study was the implementation of a methodology capable of providing comparable results. To achieve this, an extension of the ESRI ArcGIS v.10 software was employed as published by USGS-(Digital Shoreline Analysis System v.4.3). The DSAS extension lets the user define a constant straight line in a specific distance from the shoreline and take crosssections perpendicular to it among the evolving coastlines (Fig.2). The measurements give quantitative information on the change of the position of the shoreline, as well as more useful statistical data. The distance between cross-sections was set at $100 \mathrm{~m}$. 


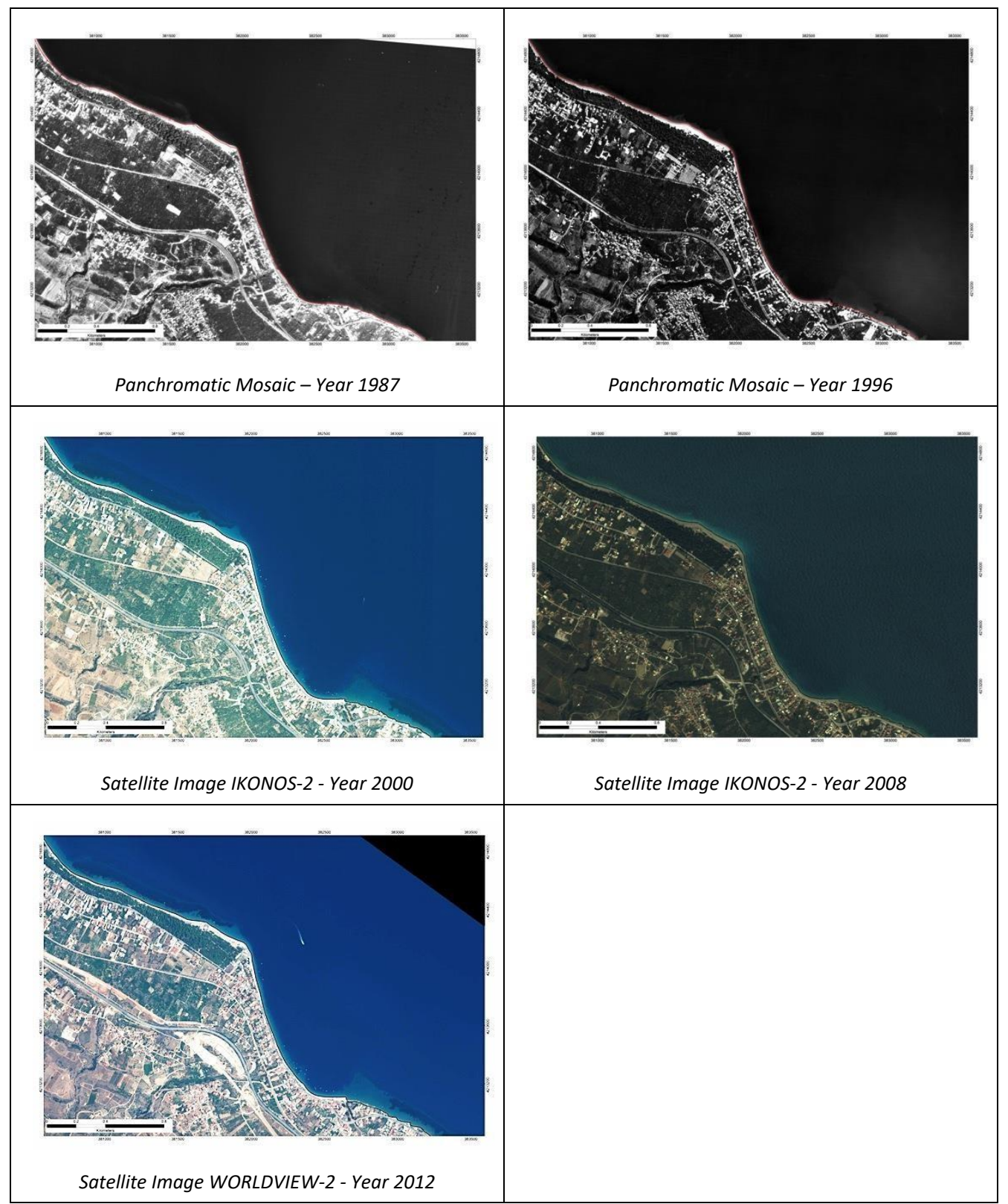

Figure 1 - Sample of the remote sensing data for the area between Xylokastro - Sykia. Changes regarding the shoreline as well as the land are visible. All data have been referenced into GGRS'87 projection system.

A total number of 145 cross-sections were created covering a $14.5 \mathrm{~km}$ waterfront, in order to estimate the evolution of the shoreline and quantify the rate of change between 1987 and 2012. For each section five measurements were conducted, one for each time series regarding the absolute distance between every digitized shoreline and a given baseline, which was digitized 50 meters offshore the oldest shoreline trace. The table containing the statistical data can be used either to produce graphs (Fig.3) or visualize them in a GIS environment. 


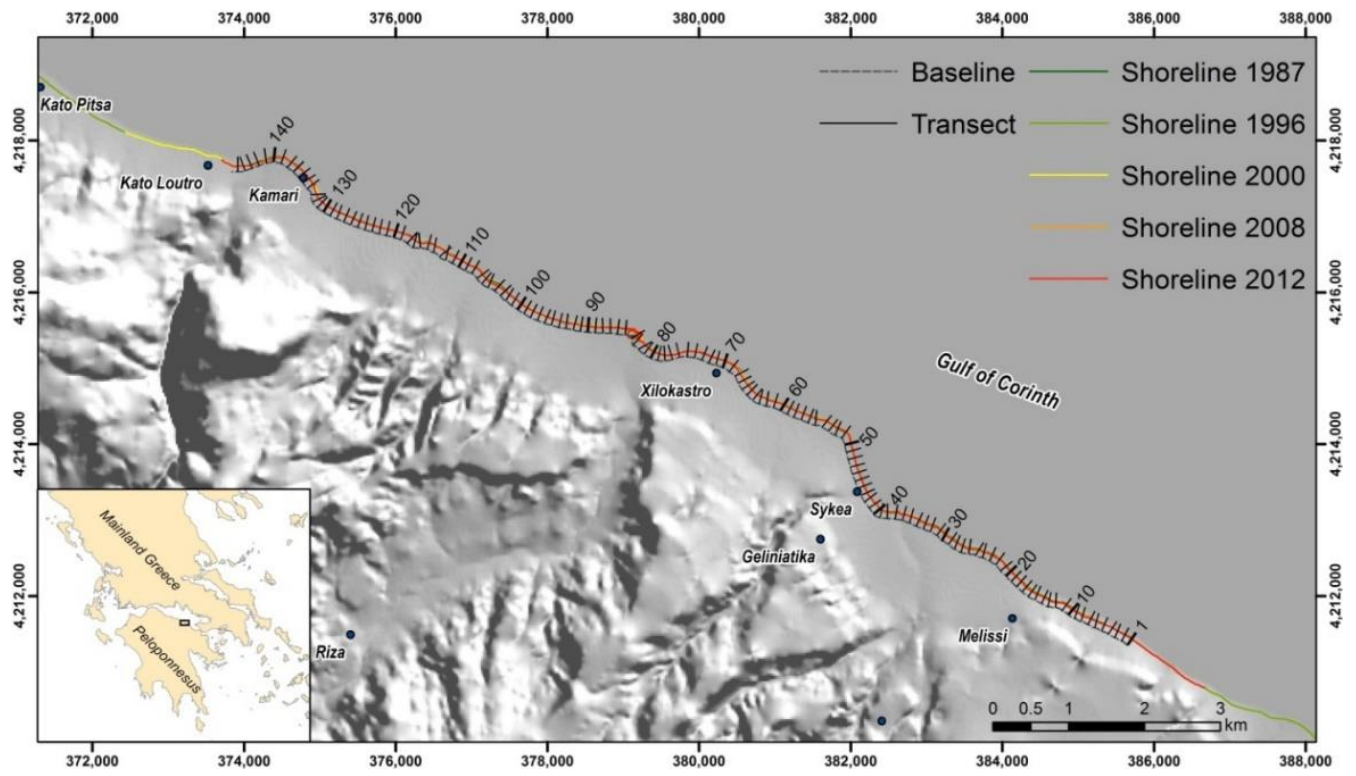

Figure 2 - Location of the 145 cross-sections which were used for calculating the shoreline change. The coastline traces for each time period are also presented. The inset shows the exact location of the study area in Greece.

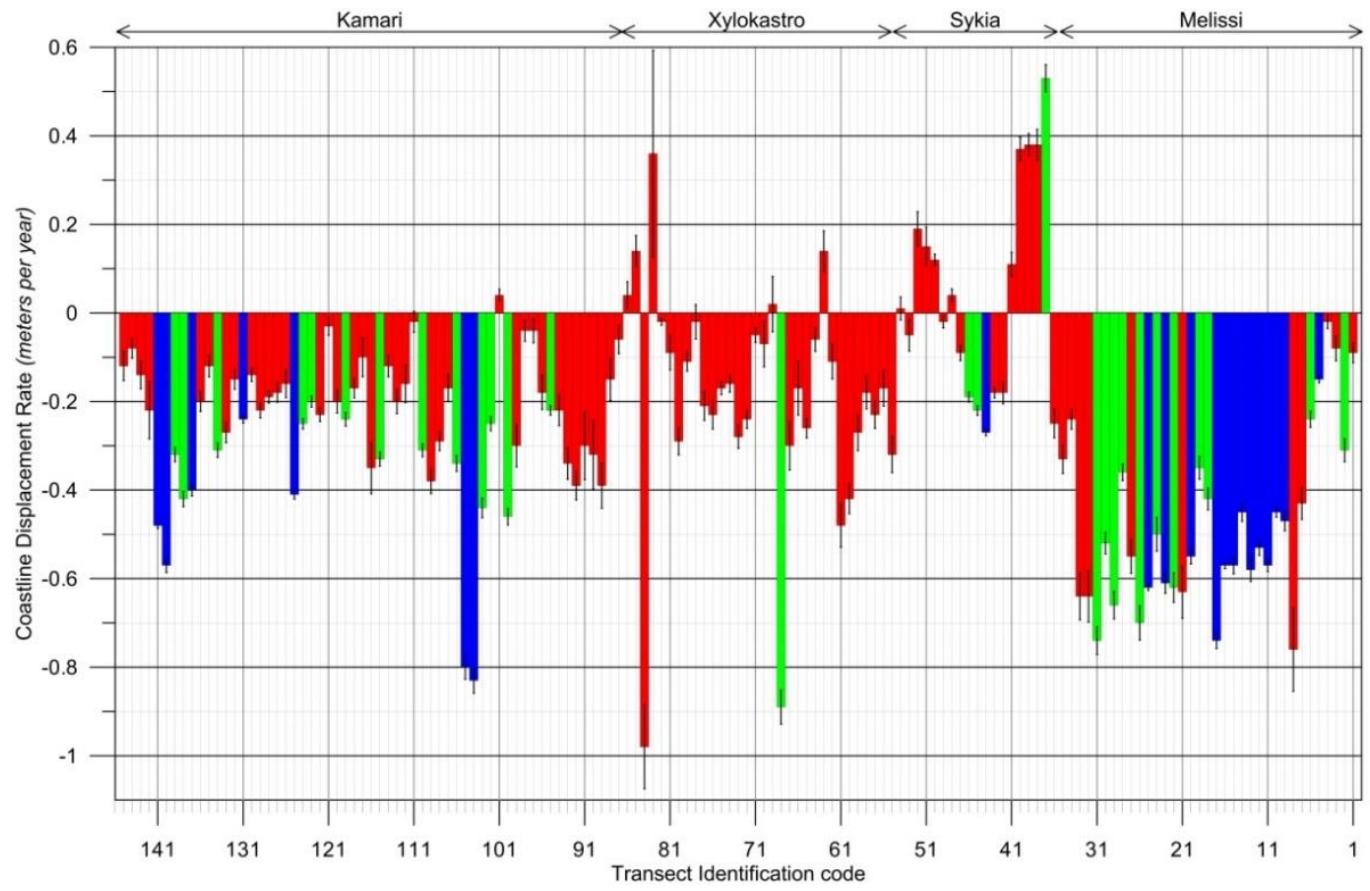

Figure 3 - Statistic charts showing the deposition rates (+) or erosion rates (-) in each section along a $14.5 \mathrm{~km}$ coastal front (exact location is presented at the top of the graph). The colour group is based on the R-squared of Linear Regression (Blue:>0.95, Green:0.90-0.94, Red: $<0.90$ ). 


\section{Field Observations}

At the easternmost part of the study area, at the coastal front of the village Melissi (cross-sections 1-36), the phenomenon of beach erosion is severe. This was clearly observed after the interpretation of the aerial images of 1987 and 1996, as well as the satellite images and it was verified during the ground truth procedure. The shoreline analysis resulted impressively well correlations yielding that the coastline has been retrograding significantly since 1987 with an average rate of $0.48 \mathrm{~m} / \mathrm{yr}$, while the maximum well correlated erosion rate $(0.74 \mathrm{~m} / \mathrm{yr})$ was calculated at transect 17 (fig. 3$)$. This is partly due to the growth of Melissi village on the shore without any initial coastal protection constructions.

Even if the seaside structures have been reinforced in order to avoid foundation failures, the severe damages at the seaside road are considered quite important, as the specific road is the main transportation route in the wider area. Along the westernmost coastline of this area a retaining wall of $150 \mathrm{~m}$ total length has been constructed as an erosion protection measure. The wave erosive action is obvious both at the base of the retaining wall, as well as along the coastal road which has been seriously damaged (fig. 4).

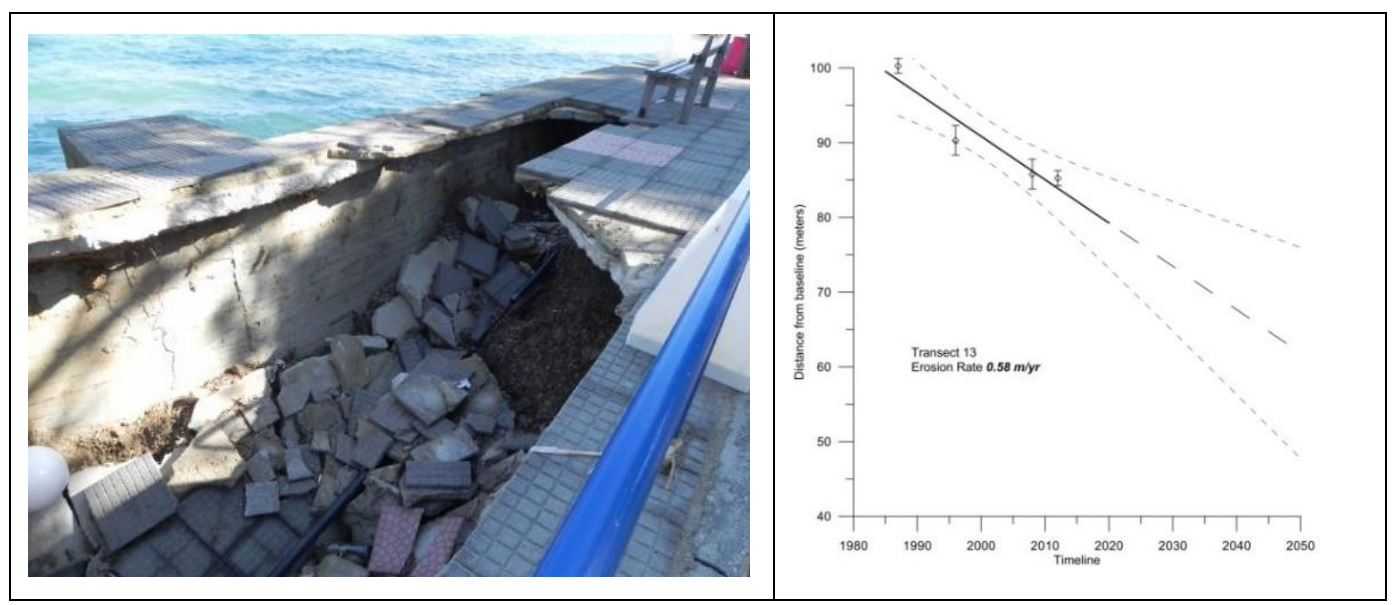

Figure 4 - Damages at the retaining wall at the location of transect 13 , where the erosion rate was calculated at $0.58 \mathrm{~m} / \mathrm{yr}$.

Moving westwards, along the beach front of the village Sykia (cross-sections 37-54), we find the only coastline part where progradation is observed. The main reason is because at the borders between the villages Melissi and Sykia, break water piers have been constructed using natural boulders. The boulders were installed across the sea side as an erosion protection measure (fig. 5). At some points the piers have been submerged in the seawater due to severe wave erosive actions but a great amount of transported material is deposited at several parts between the piers. The most effective results were found at the location of transect 37 , where the calculated rate was at $0.53 \mathrm{~m} / \mathrm{yr}$ (fig. 3), but this seems to be a very local exception, as the most well correlated results were calculated at transect 44 with erosion rate of the order of $0.27 \mathrm{~m} / \mathrm{yr}$.

The cross-sections 55-81 are located at the Xilokastro beach-side zone where sediment is accumulated by the river Sythas, but it seems that it is not enough for keeping the coastline from retrograding. Therefore a retaining wall has been gradually constructed for the protection of the sea side road at a total length of $1.5 \mathrm{~km}$. The construction of the first and second section of the retaining wall was completed during 1969 and 1985, respectively. Later on, the wall was reinforced furthermore by installing natural protective boulders (fig. 6). During 1993, break water piers were constructed along the seaside up to the main square of Xilokastro in order to create a tombolo by using the large sediment quantities of Sythas River, but the shoreline along the coastal zone kept 
receding. The latter was caused either by the eroding action of waves as well as because the potential material transfer by the river has been decreased due to the use of large amounts of river sediment in several constructions and as replacement material in highly eroded areas of the beach. The best correlated measurements were observed at transect 68 , where the erosion rate was calculated at 0.89 $\mathrm{m} / \mathrm{yr}$ and it seems that if no protection measures were taken (despite their efficiency) another 30 meters of retrogradation would have been observed till 2045.
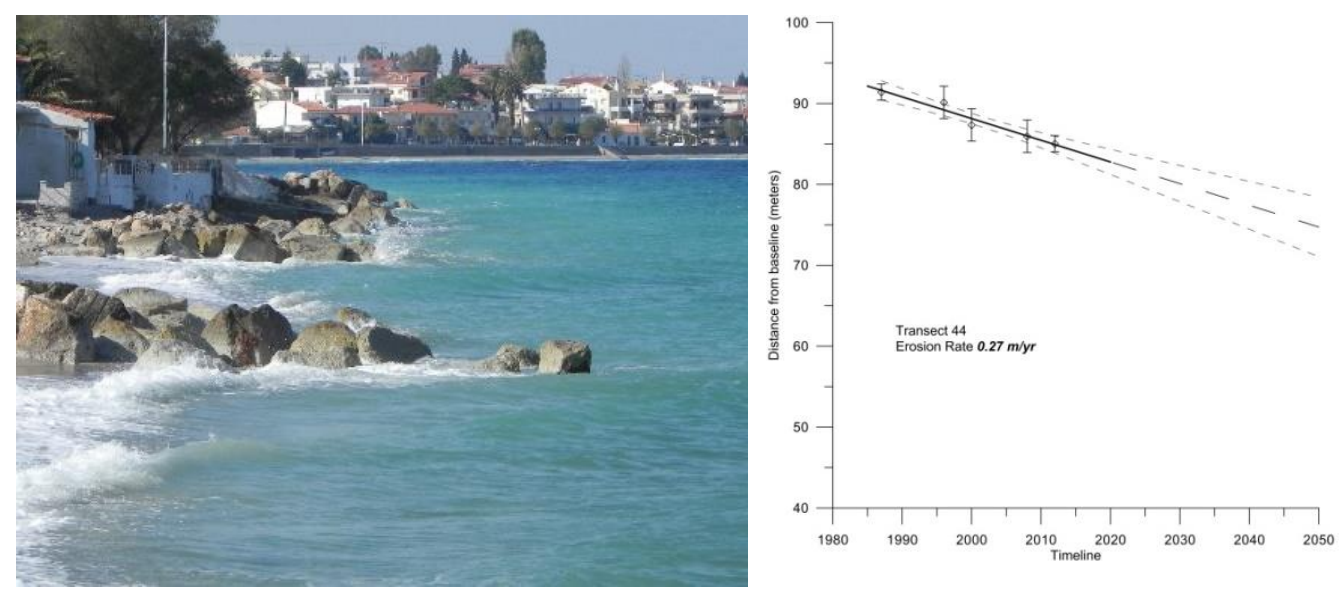

Figure 5 - Break water piers using natural boulders across the waterfront of Sykia village do not seem to have solved the retrogradation phenomenon, as at the location of transect 44 the erosion rate was calculated at $0.27 \mathrm{~m} / \mathrm{yr}$.
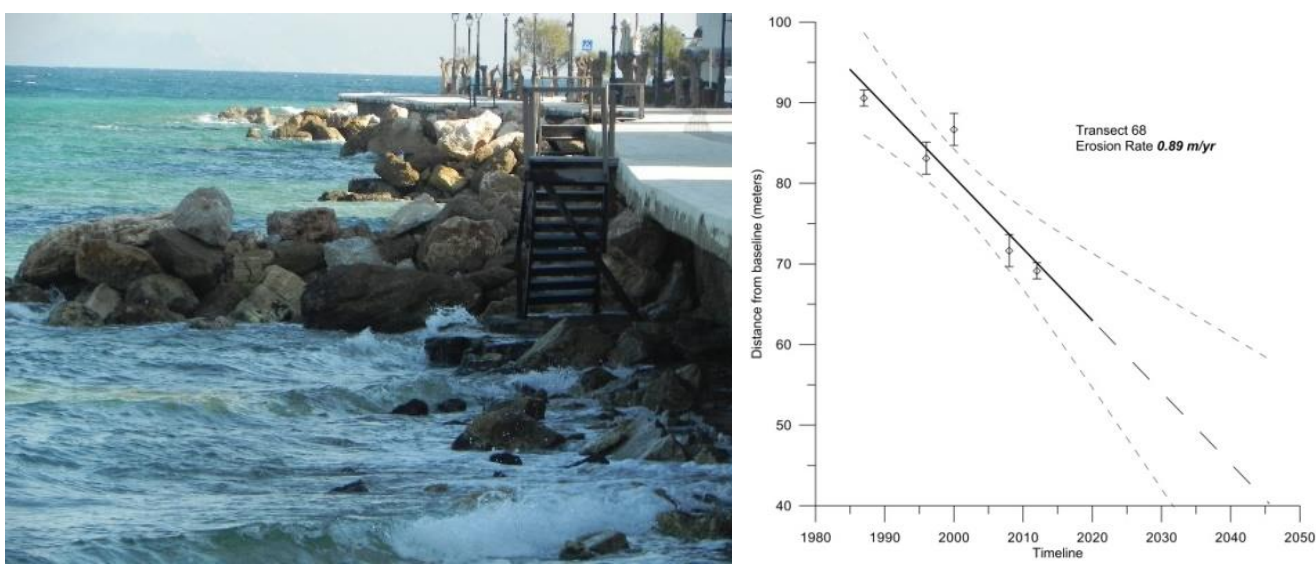

Figure 6 - Inefficient constructions did not prevent the severe damages at the location of transect 68 where the erosion rate was calculated at $0.89 \mathrm{~m} / \mathrm{yr}$.

Westward of the yacht marina of Xilokastro (transects 83-84), which was completed during 1987, lies the beach zone of Kamari (cross-sections 87-145). In the boundary between those areas two river estuaries are located. However, Spartilas River and Kolones River are quite small with reduced capability of sediment transportation. Additionally, at the beach of Kamari another river, called Arachovitikos joins the gulf, but in every case the potential sediment transportation is not enough to replenish the erosion induced by the wave action. The erosion phenomena are apparent even along the estuary zone. The average erosion rate observed along the westernmost $6 \mathrm{~km}$ of the study area reaches the order of $0.26 \mathrm{~m} / \mathrm{yr}$, but the maximum calculated retrogradation rate was found at the location of transect $104(0.82 \mathrm{~m} / \mathrm{yr}$ with $0.91 \mathrm{R}$-squared of Linear Regression). It should be 
highlighted that the building activity has been expanded on the beach in many cases and the seaside has been reinforced using natural boulders, especially on building areas (fig. 7).
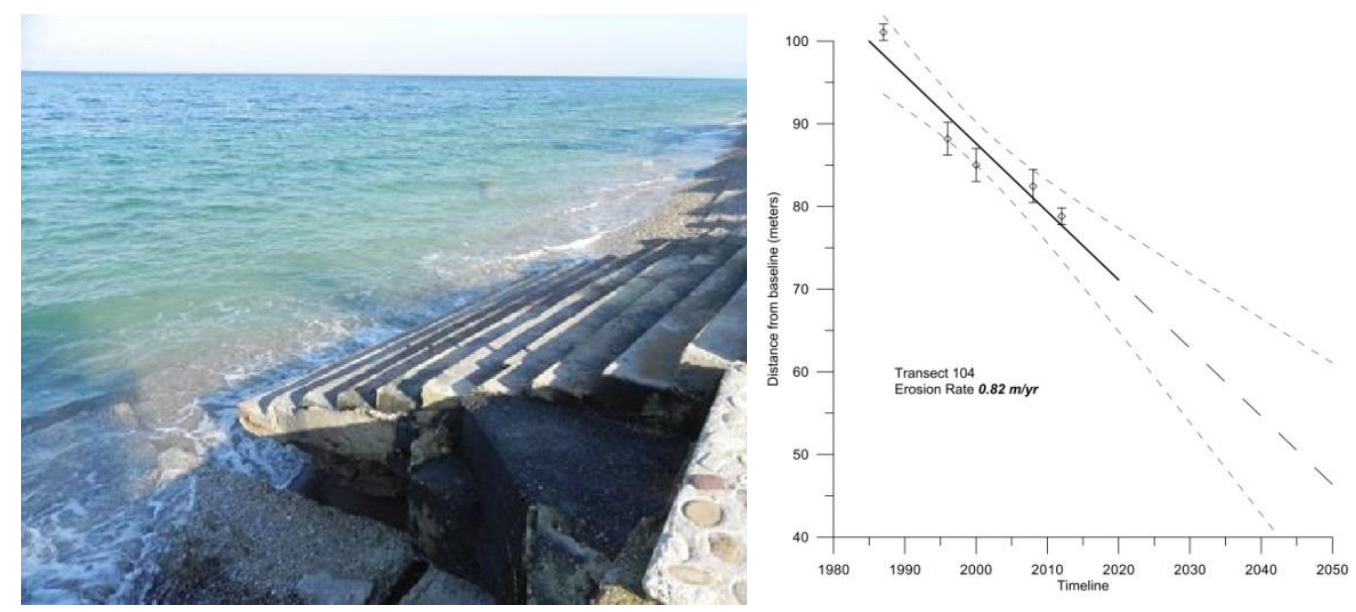

Figure 7 - Location of transect, 104 at the beachfront of Kamari, where coastal erosion along with failures to infrastructures are observed.

\section{Conclusions}

The analysis of historic analog panchromatic aerial images and contemporary digital high-resolution multi-spectral satellite images, combined in a Geographic Information System platform proved to be a useful tool in determining and quantifying the shoreline displacement rate and especially the erosion rate at developing suburbs.

By employing the methodology described above, at the area of investigation we have calculated the displacement rate of the coastline position over the past 30 years. The rates of change that were calculated were not homogeneous along the full length of the coastline. Specifically, the average value of the rate of receding is $24 \mathrm{~mm} / \mathrm{year}$, while extreme values of order $1 \mathrm{~m} /$ year were also observed, increasing the riskiness of specific positions. In those positions it has been estimated that the shoreline has receded over $20 \mathrm{~m}$ in the last 25 years and is strongly affected by the human activity. Thus, taking protective measures are of highest importance.

\section{References}

Alhin, K.A. and Niemeyer, I., 2009. Coastal monitoring using remote sensing and geoinformation systems: estimation of erosion and accretion rates along gaza coastline. In: Geoscience and Remote Sensing Symposium, 2009 IEEE International, IGARSS 2009, 4, IV-29, IEEE.

Anthoff, D., Nicholls, R.J. and Tol, R.S., 2010. The economic impact of substantial sea-level rise, Mitigation and Adaptation Strategies for Global Change, 15(4), 321-335.

Boak, E.H. and Turner, I.L., 2005. Shoreline definition and detection: a review, Journal of Coastal Research, 21(4), 688-703.

Chaaban, F., Darwishe, H., Battiau-Queney, Y., Louche, B., Masson, E., Khattabi, J.E. and Carlier, E., 2012. Using Arcgis modelbuilder and aerial photographs to measure coastline retreat and advance North of France, Journal of Coastal Research, 28(6), 1567-1579.

De Pippo, T., Donadio, C., Pennetta, M., Petrosino, C., Terlizzi, F. and Valente, A., 2008. Coastal hazard assessment and mapping in northern Campania, Italy, Geomorphology, 97(3), 451-466.

Evans, E., Ashley, R., Hall, J., Penning-Rowsell, E., Saul, A., Sayers, P., Thorne, C. and Watkinson, A., 2004. Foresight Future Flooding, Scientific Summary: Volume I: Future risks and their Drivers, Office of Science and Technology, London. 
Gens, R., 2010. Remote sensing of coastlines: detection, extraction and monitoring, International Journal of Remote Sensing, 31(7), 1819-1836.

Hollenstein, C., Mueller, M., Geiger, A. and Kahle, H.G., 2008. Crustal motion and deformation in Greece from a decade of GPS measurements, 1993-2003, Tectonophysics, 449(1), 17-40.

Kloehn, K.K., Beechie, T.J., Morley, S.A., Coe, H.J. and Duda, J.J., 2008. Influence of dams on river-floodplain dynamics in the Elwha river, Washington, Northwest Science, 82(sp1), 224-235.

Malthus, T.J. and Mumby, P.J., 2003. Remote sensing of the coastal zone: an overview and priorities for future research.

McClusky, S., Balassanian, S., Barka, A., Demir, C., Ergintav, S., Georgiev, I., Gurkan, O., Hamburger, M., Hurst, K. and Kahle, H., 2000. Global positioning system constraints on plate kinematics and dynamics in the eastern Mediterranean and Caucasus, Journal of Geophysical Research, Solid Earth (1978-2012), 105(B3), 5695-5719.

Moore, L.J., 2000. Shoreline mapping techniques, Journal of Coastal Research, 16(1), 111-124.

Mugnier, C., 2002. Grids and datums: The hellenic republic. Photogramm, Eng. Remote Sens., 68, $1237-1238$

Nicholls, R. and Hoozemans, F., 1996. The mediterranean: vulnerability to coastal implications of climate change, Ocean and Coastal Management, 31(2), 105-132.

Rijn, L.C.v., 1998. Principles of Coastal Morphology, Aqua Publications, Amsterdam, The Netherlands.

Valaouris, A., Poulos, S., Petrakis, S., Alexandrakis, G., Vassilakis, E. and Ghionis G., 2014. Processes affecting recent and future evolution of the Xylokastro beach zone (semi-enclosed Gulf of Corinth, Greece), Global NESTJournal, 16(4), 773-786.

Vassilakis, E., Skourtsos, E. and Kranis, H., 2007. Combination of morphometric indices as a method for the quantification of neotectonic evolution in active areas. In: 16th DRT Conference, Nuova Serie 5. Rend., Soc. Geol. It., Milan, 214.

Vassilakis, E., 2010. Remote sensing of environmental change in the antirio deltaic fan region, Western Greece., Remote Sensing, 2, 2547-2560.

Vassilakis, E., Royden, L. and Papanikolaou, D., 2011. Kinematic links between subduction along the Hellenic trench and extension in the gulf of Corinth, Greece: A multidisciplinary analysis, Earth and Planetary Science Letters, 303(1), 108-120.

Vassilakis, E. and Papadopoulou-Vrynioti, K., 2014. Quantification of deltaic coastal zone change based on multi-temporal high resolution earth observation techniques, ISPRS International Journal of Geo-Information, 3(1), 18-28. 